\title{
Effects of Wet Etch Processing on Laser-Induced Damage of Fused Silica Surfaces
}

\author{
C. L. Battersby \\ L. M. Sheehan \\ M. R. Kozlowski
}

This paper was prepared for submittal to the 30th Boulder Damage Symposium: Annual Symposium on Optical Materials for High Power Lasers

Boulder, Colorado

September 28 - October 1, 1998

December 22, 1998

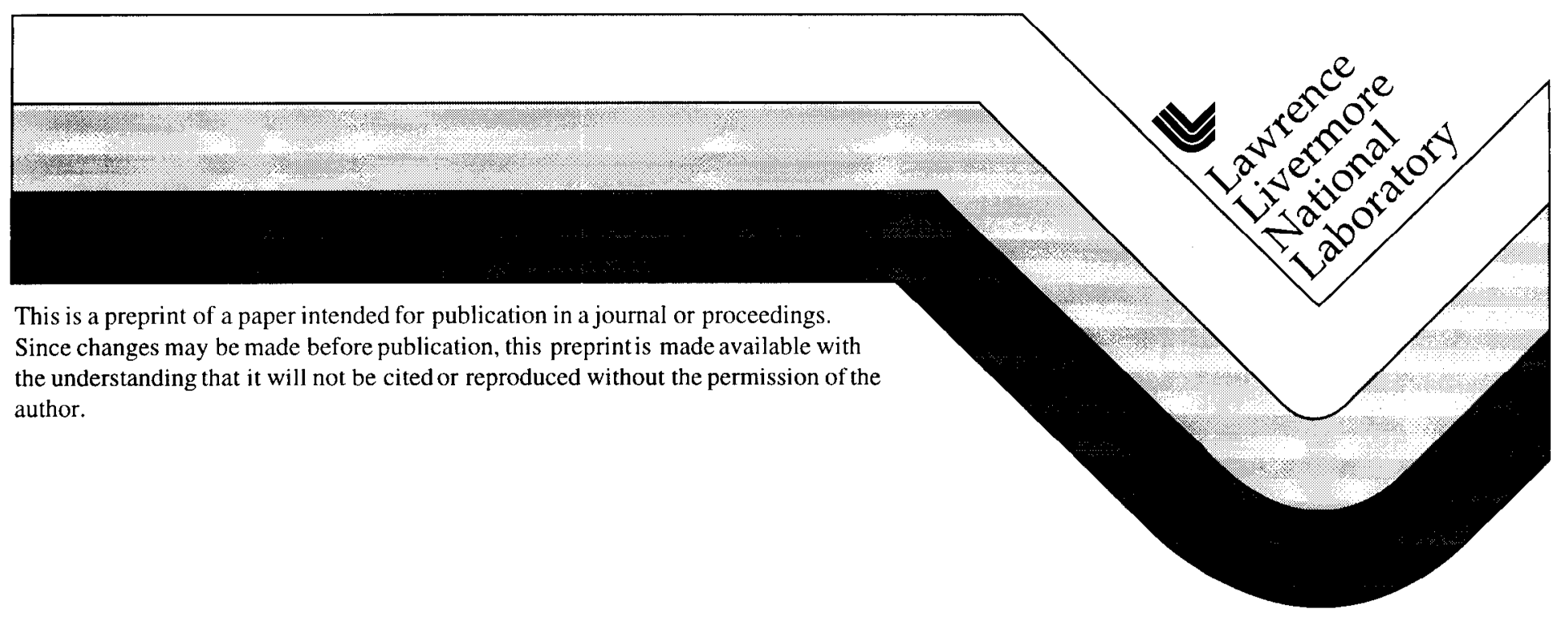




\section{DISCLAIMER}

This document was prepared as an account of work sponsored by an agency of the United States Government. Neither the United States Government nor the University of California nor any of their employees, makes any warranty, express or implied, or assumes any legal liability or responsibility for the accuracy, completeness, or usefulness of any information, apparatus, product, or process disclosed, or represents that its use would not infringe privately owned rights. Reference herein to any specific commercial product, process, or service by trade name, trademark, manufacturer, or otherwise, does not necessarily constitute or imply its endorsement, recommendation, or favoring by the United States Government or the University of California. The views and opinions of authors expressed herein do not necessarily state or reflect those of the United States Government or the University of California, and shall not be used for advertising or product endorsement purposes. 


\title{
Effects of Wet Etch Processing on Laser-Induced Damage of Fused Silica Surfaces
}

\author{
Colin L. Battersby, Lynn M. Sheehan, Mark R. Kozlowski \\ University of California \\ Lawrence Livermore National Laboratory \\ P. O. Box 808 , L-496 \\ Livermore, CA 94550
}

\begin{abstract}
Laser-induced damage of transparent fused silica optical components by $355 \mathrm{~nm}$ illumination occurs primarily at surface defects produced during the grinding and polishing processes. These defects can either be surface defects or sub-surface damage. Wet etch processing in a buffered hydrogen fluoride (HF) solution has been examined as a tool for characterizing such defects.

A study was conducted to understand the effects of etch depth on the damage threshold of fused silica substrates. The study used a $355 \mathrm{~nm}, 7.5 \mathrm{~ns}, 10 \mathrm{~Hz} \mathrm{Nd:YAG} \mathrm{laser} \mathrm{to} \mathrm{damage} \mathrm{test} \mathrm{fused} \mathrm{silica} \mathrm{optics}$ through various wet etch processing steps. Inspection of the surface quality was performed with Nomarski microscopy and Total Internal Reflection Microscopy. The damage test data and inspection results were correlated with polishing process specifics. The results show that a wet etch exposes subsurface damage while maintaining or improving the laser damage performance. The benefits of a wet etch must be evaluated for each polishing process.
\end{abstract}

Keywords: laser-induced damage, fused silica, wet etch, hydrogen fluoride, TIRM, microscopy

\section{INTRODUCTION}

Lawrence Livermore National Laboratory (LLNL) has been evaluating wet etch processing as a tool for inspecting and/or increasing the laser-induced damage threshold of polished fused silica surfaces. It is believed a wet etch after the final polish may reveal defects hidden by the final-polish redeposition layer. A wet etch may also increase the laser-induced damage threshold by several paths: 1) remove the contaminated redeposition layer, 2) remove contaminants from sub-surface cracks, 3) blunt or remove sub-surface cracks (Figure 1). A post polish etch may, therefore, serve as a quality inspection technique and also improve the optic quality. The high density pin-point damage morphology referred to as gray haze, has been associated with $\mathrm{CeO}_{2}$ polished substrates ${ }^{1,2}$ (Figure 2). Wet etch processing has been studied as a possible remedy to gray haze on $\mathrm{CeO}_{2}$ polished parts. The observed results are shown to vary significantly with the etch depth. 


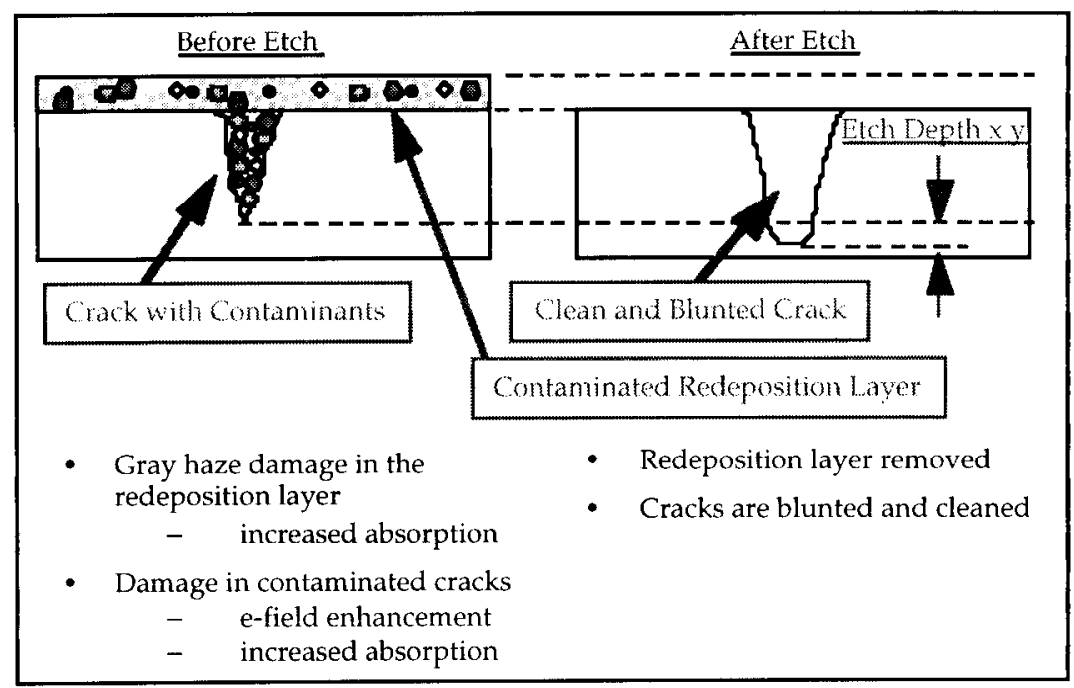

Figure 1. A simple model for damage threshold improvement through wet etch processing.
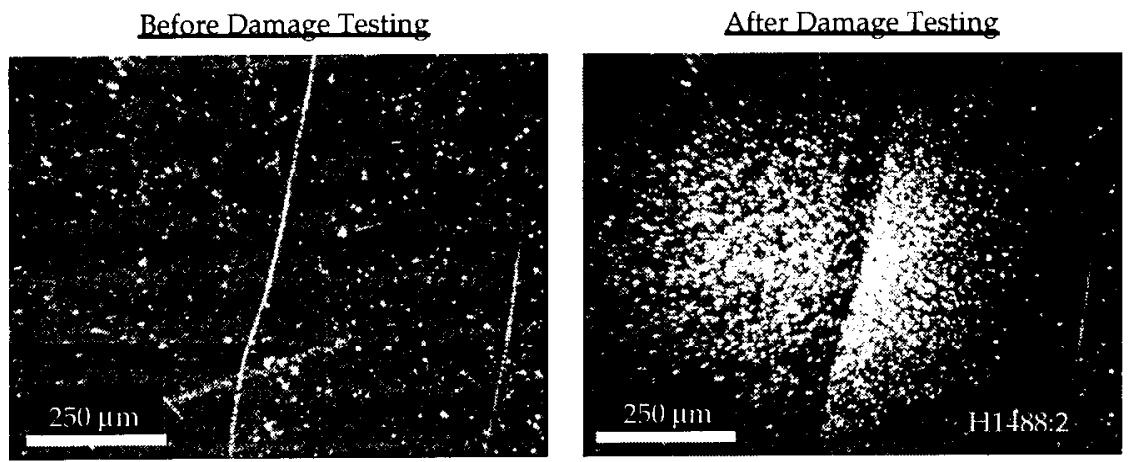

Figure 2. TIRM images of a fused silica surface prior to $355 \mathrm{~nm}$ UV irradiation (right) and the high density pin point (gray haze) damage after illumination at $15.5 \mathrm{~J} / \mathrm{cm}^{2}, 3.0 \mathrm{~ns}$ (left).

Three experiments were conducted using parts fabricated by three different vendors as tabulated in Table 1. Two parts were high damage threshold $\mathrm{CeO}_{2}$ polished substrates, which showed signs of gray haze in the pre-etch damage tests. The third part was a high damage threshold $\mathrm{ZrO}_{2}$ polished substrate and did not show signs of gray haze.

Table 1. Vendor and part description.

\begin{tabular}{|c|c|c|c|}
\hline Part \# & Vendor & $\begin{array}{c}\text { Final } \\
\text { Polish }\end{array}$ & $\begin{array}{c}\text { Pre-etch } \\
\text { Gray Haze }\end{array}$ \\
\hline 1 & 1 & $\mathrm{CeO}_{2}$ & Yes \\
\hline 2 & 2 & $\mathrm{CeO}_{2}$ & Yes \\
\hline 3 & 3 & $\mathrm{ZrO}_{2}$ & No \\
\hline
\end{tabular}

The wet etch used for this experiment was a buffered hydrogen fluoride solution $\left(1 \% \mathrm{HF} / 15 \% \mathrm{NH}_{4}\right)$. Etching was done through partial immersion of the part into the etch solution, allowing simultaneous etching of both sides of the optic. The hydrogen fluoride solution provides an etch rate of $11 \mathrm{~nm} / \mathrm{min}$ and the etch depth error was $\pm 10 \mathrm{~nm}$.

Parts 2 and 3 were inspected post-etch with Total Internal Reflection Microscopy (TIRM). TIRM is a darkfield microscopy method which involves injecting a $488 \mathrm{~nm}$ Argon-Ion laser beam into a prism 
coupled to the substrate with an index matching mineral oil. ${ }^{2}$ The beam is injected at an angle greater than or equal to the critical angle. The resulting images highlight scattering defects. An example of a TIRM image can be seen in the images of Figure 2. The images are analyzed to determine particle count and percent obscured area. The measured percent obscured area is an overestimate of the actual value because of the resolution limitations of our equipment and inherent errors in scatter based techniques. However, the measured obscured area gives a relative measure to the area of the visible defects.

\section{EXPERIMENTAL SETUP}

The Automated Damage Test (ADT) system is a facility at Lawrence Livermore National Laboratory. ${ }^{3}$ It is used for damage test experiments on up to $8^{\prime \prime}$ diameter parts. The system consists of an Nd:YAG laser converted to $355 \mathrm{~nm}$ at $10 \mathrm{~Hz}$ with a $7.5 \mathrm{~ns}$ pulse duration. The samples were illuminated with an approximate $1 \mathrm{~mm} 1 / \mathrm{e}^{2}$ diameter gaussian beam. The angle of incidence was $20^{\circ}$ and the beam was $\mathrm{P}$ polarized.

l'he primary damage tests procedures implemented with ADT are raster scans and R:1 maps. Scatter diagnostics are used to detect laser-induced damage in both tests. The scatter diagnostics recognize a change in scatter, indicating the occurrence of damage. ${ }^{4,5}$ Raster scan damage tests are used to look for low probability damage sites. The raster scan test consists of scanning an approximate $1 \mathrm{~mm} 1 / \mathrm{e}^{2}$ gaussian beam over an area at a scan increment of $90 \%$ of the beam diameter. For raster scan tests the fluence is increased after each non-damaging scan and the area is scanned again. The raster scans are repeated until damage occurs. ${ }^{1,5}$ The $R: 1$ maps provide information on the statistical distribution of damage threshold on a part. The R:1 test consists of ramping the fluence on a site until damage is detected. The fluence at which damage is detected is the damage threshold for that one site. The R:1 map typically consists of tests of 16-100 sites to obtain a reliable statistical distribution.

The R:1 mapping test will be summarized in the following discussion using the maximum, average, and minimum values indicated in Figure 3. An example of the R:1 test distribution is shown in Figure 3. The raster scan test results are summarized using two values: 1) raster scan average: The average between the fluence where catastrophic damage was first initiated and the previous scans fluence. 2) gray haze average: The average between the fluence where gray haze was first witnessed and the previous scans fluence. The gray haze average may be reported as a greater-than value if the gray haze damage morphology was not witnessed prior to catastrophic failure. Gray haze is determined by examination with the eye aided by an intense white light source.

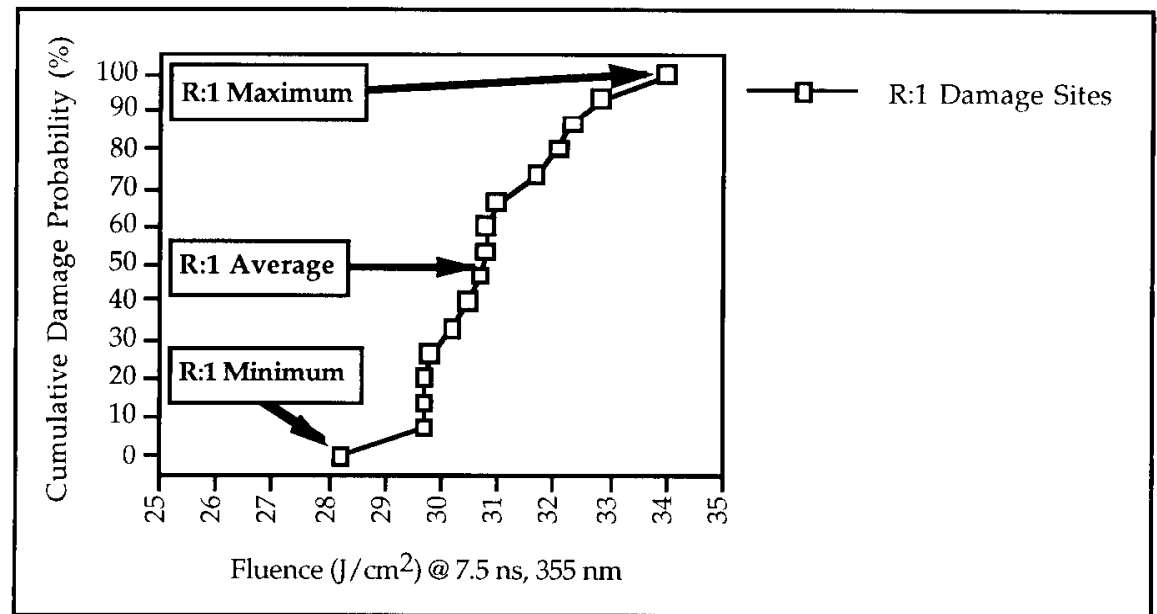

Figure 3. Example of an R:1 map distribution curve and an explanation of the statistical data points.

The R:1 maps for this experiment were 16 site tests with a 600 pulse ramp from $2 \mathrm{~J} / \mathrm{cm}^{2}$ to $50 \mathrm{~J} / \mathrm{cm}^{2}$. The rasters scan tests were in $25 \mathrm{~mm}^{2}$ areas with a scan increment of $0.15 \mathrm{~mm}$. 
The data used for analysis was collected from the rear or output surface. All damage test data reflects fluence levels on the rear surface. Any front or input surface damage data was removed from the analysis. The Automated Damage Test system experiences errors of $\pm 15 \%$ on fluence measurements.

\section{RESULTS}

\subsection{Vendor 1}

The first experiment was a look at etch depth versus damage threshold of a $\mathrm{CeO}_{2}$ polished part. A 6" diameter $\mathrm{CeO}_{2}$ polished substrate by Vendor 1 was used for the study. The part was etched on both sides in $300 \mathrm{~nm}$ increments and damage tested after each etch. The etch and test was repeatcd up to a depth of $1800 \mathrm{~nm}$. The part was tested using R:1 and raster scan damage tests. The results from the damage tests were used to see the effect of etch depth on the removal of the gray haze damage morphology, the laser-induced damage threshold, and the consistency of both sides of the part. The test results are summarized in Figure 4.

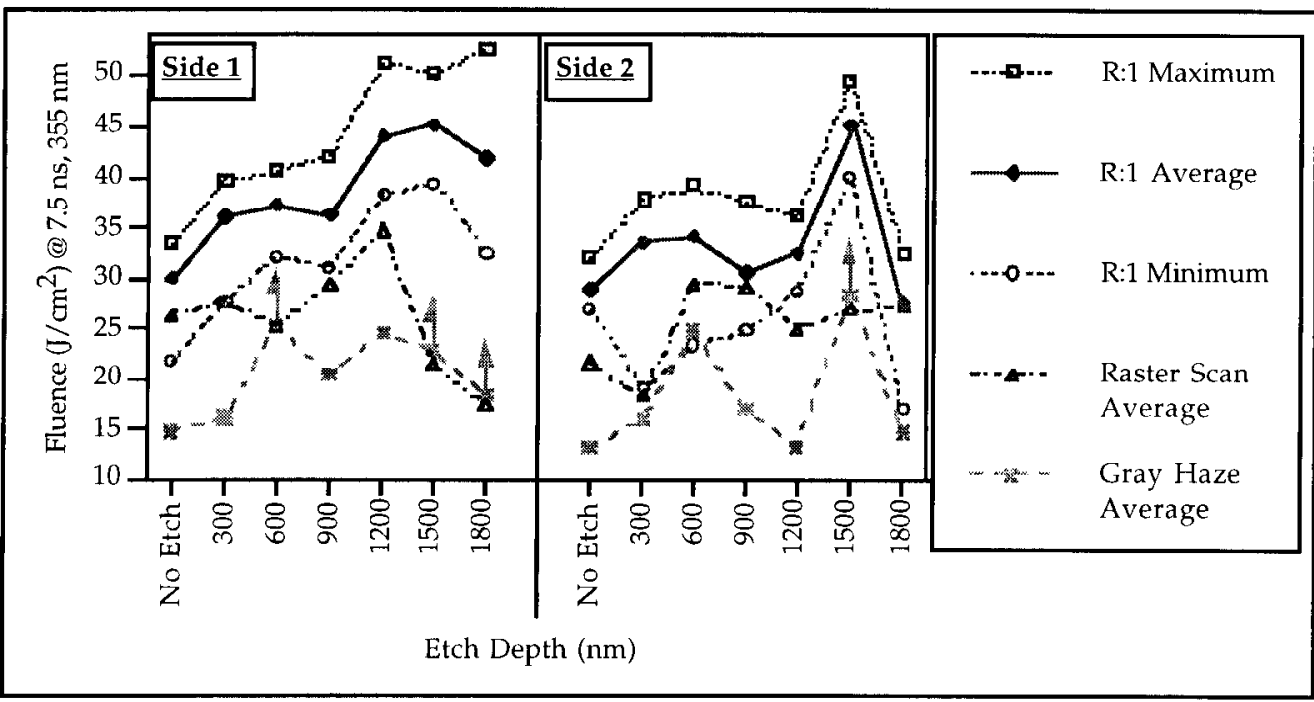

Figure 4. Comparison of laser-induced damage threshold statistics as a function of etch depth for both sides of the Vendor $1, \mathrm{CeO}_{2}$ polished fused silica substrate.

Part 1 was a high damage threshold part, but suffered from the gray haze damage morphology at low fluence levels. Etching significantly altered the damage threshold of the part. The gray haze average increased after $600 \mathrm{~nm}$ etch removal from both sides. The virtual disappearance of gray haze on both sides at $600 \mathrm{~nm}$ and $1500 \mathrm{~nm}$ and reappearance of a similar damage morphology at $900 \mathrm{~nm}$ and $1800 \mathrm{~mm}$ suggests varying levels of contamination, sub-surface damage, or redeposition of contaminants at these approximate etch depths. The continual decrease in raster scan average from $1200 \mathrm{~nm}$ to $1800 \mathrm{~nm}$ on side 1 suggests the etch may have revealed gross defects that fail catastrophically at lower fluence levels. The same type of decrease was witnessed for all performance metrics measured on side 2 at depths of $1500 \mathrm{~nm}$ to $1800 \mathrm{~nm}$. Side 1 and side 2 had different damage threshold responses to each etch step.

\subsection{Vendor 2}

The second experiment involved testing a layered etched part. The sample was a 6" diameter $\mathrm{CeO}_{2}$ polished part fabricated by Vendor 2. The part showed signs of gray haze in pre-etch damage tests. The experiment involved etching the part in a step like form. The part was etched to different etch depths in approximately 1" increments across the part. The etch was performed using a dip method so there were areas of no etch, $300 \mathrm{~nm}, 600 \mathrm{~nm}, 800 \mathrm{~nm}$, and $1500 \mathrm{~mm}$ of etch depth. The part was damage 
tested using R:1 and raster scan damage test tcchniques, and post-test inspected via Nomarski microscopy and Total Internal Reflection Microscopy (TIRM).

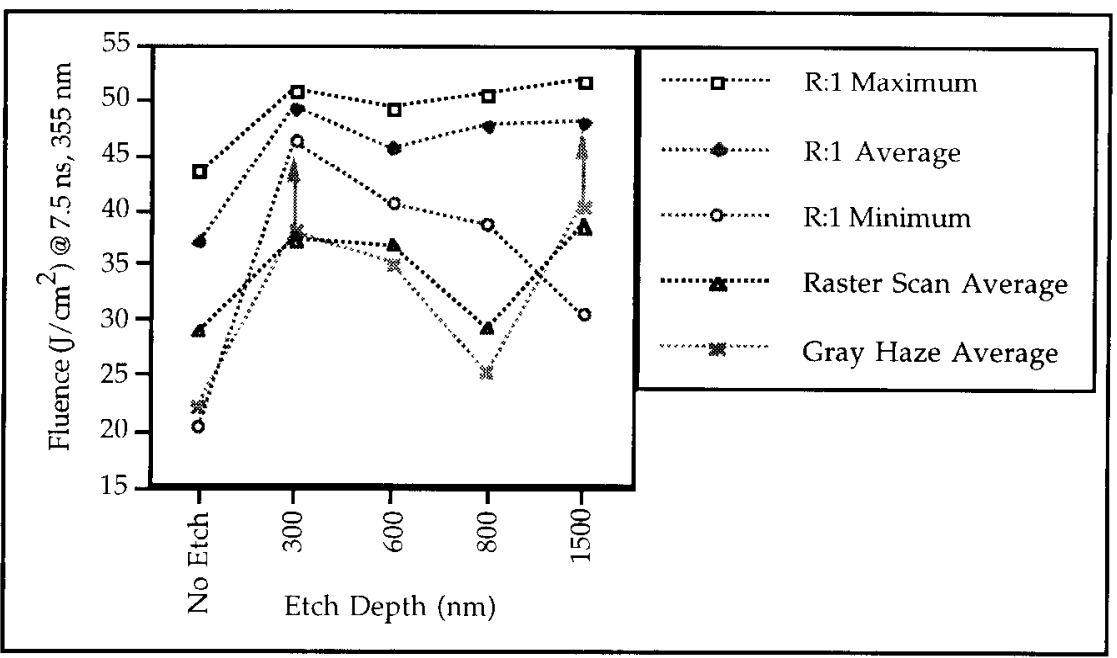

Figure 5. Comparison of laser-induced damage threshold statistics as a function of etch depth for side 1 of the Vendor 2, $\mathrm{CeO}_{2}$ polished fused silica substrate.

The gray haze on the unetched surface has been correlated with the $\mathrm{CeO}_{2}$ polishing process. ${ }^{1}$ Elimination of the gray haze damage morphology effectively occurs at etch depths of $300 \mathrm{~nm}$ and 1500 $\mathrm{nm}$. Gray haze was visible on the unetched surface, and a damage morphology similar to gray haze was witnessed at $600 \mathrm{~nm}$ and $800 \mathrm{~nm}$ etch depth. The presence of a gray haze morphology at $600 \mathrm{rm}$ and $800 \mathrm{~nm}$ may be associated with the redeposition or concentration of contaminants on the etched surface. It may also be associated with the performance of a second type of defect which has characteristics similar to the gray haze damage.

Total Internal Reflection Microscopy (TIRM) and Nomarski microscopy inspection and analysis were conducted on this part as well as part 3. A summary of TIRM data for part 2 can be found in Figure 6 . Figure 6 summarizes the percent obscured area and particle count measured for the images found in Appendix A.1. Nomarski microscopy did not reveal any additional information.

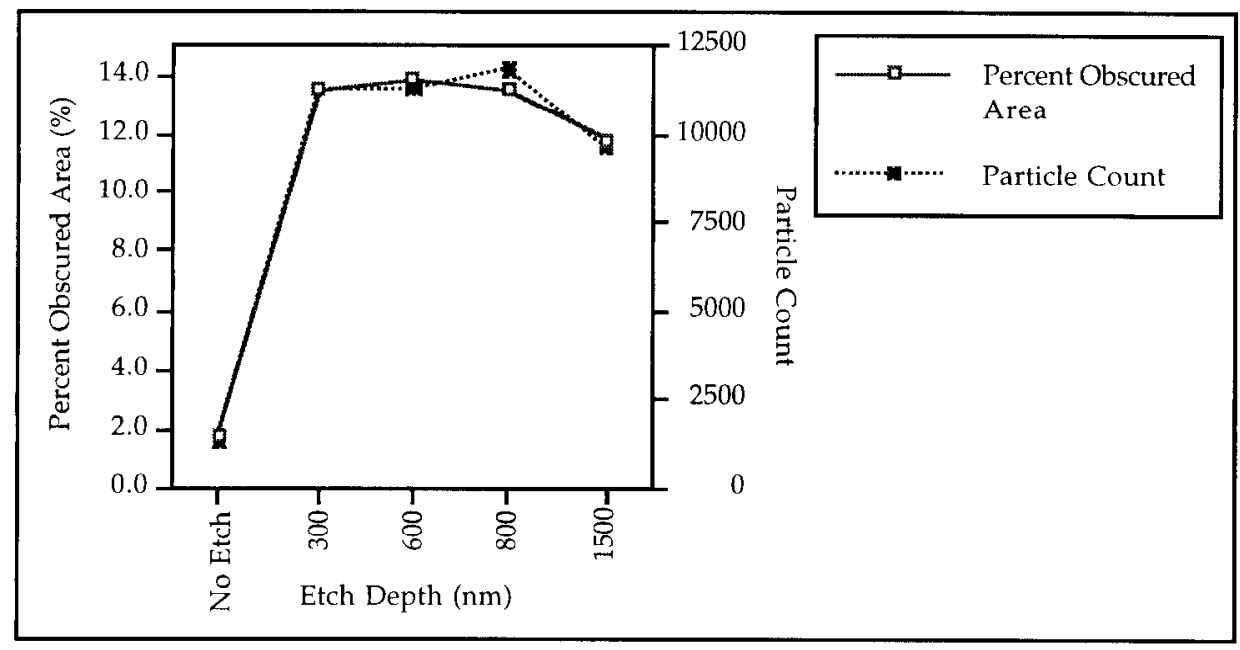

Figure 6. Comparison of the TIRM analysis of percent obscured area and particle count as a function of etch depth for side 1 of the Vendor 2, $\mathrm{CeO}_{2}$ polished fused silica substrate. 
The data summary and the images suggest that the etch exposes defects hidden by the polishing redeposition layer. It is unclear if the drop of approximately $13 \%$ in both the obscured area and particle count observed at $1500 \mathrm{~nm}$ would continue at deeper etch depths. Comparison of the obscured area and damage threshold data indicate the exposure of subsurface defects by a wet etch does not negatively effect the damage threshold performance of the surface.

\subsection{Vendor 3}

The third experiment involved testing a 6" diameter $\mathrm{ZrO}_{2}$ polished part provided by Vendor 3 using the same procedures used to test part 2. Part 3 was previously damage tested unetched and showed a high damage threshold, with no signs of gray haze.

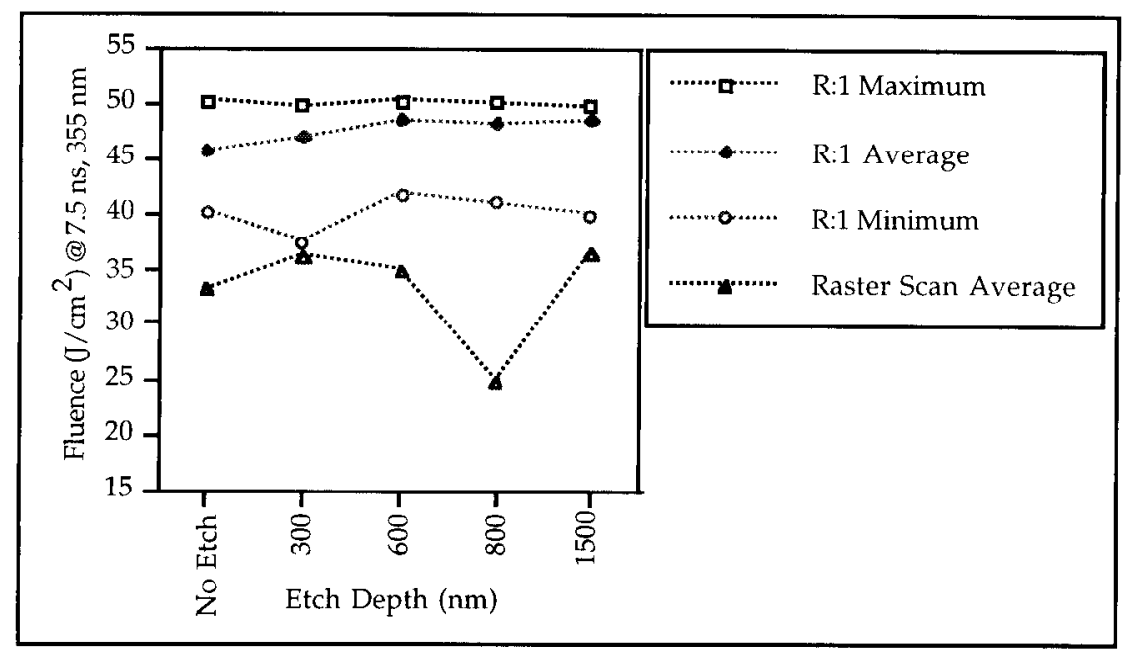

Figure 7. Comparison of laser-induced damage threshold statistics as a function of etch depth for side 1 of the Vendor $3, \mathrm{ZrO}_{2}$ polished fused silica substrate.

The data illustrated in Figure 7 shows that the part had a high initial unetched damage threshold which was not negatively effected by etch depth. The lower raster scan average at $800 \mathrm{~mm}$ may have occurred along a defect revealed by etching. To further understand the effect of etching on surface quality, TIRM and Nomarski inspection were conducted on the etched areas of the part. Figure 8 provides a summary of the measurements made on the images in Appendix A.2. The results of the etch were similar to those observed on part 2. The only clear difference between parts 2 and 3 was the removal of the gray haze damage from part 2 after the $300 \mathrm{~nm}$ etch. Once again, Nomarski microscopy did not reveal any additional information. 


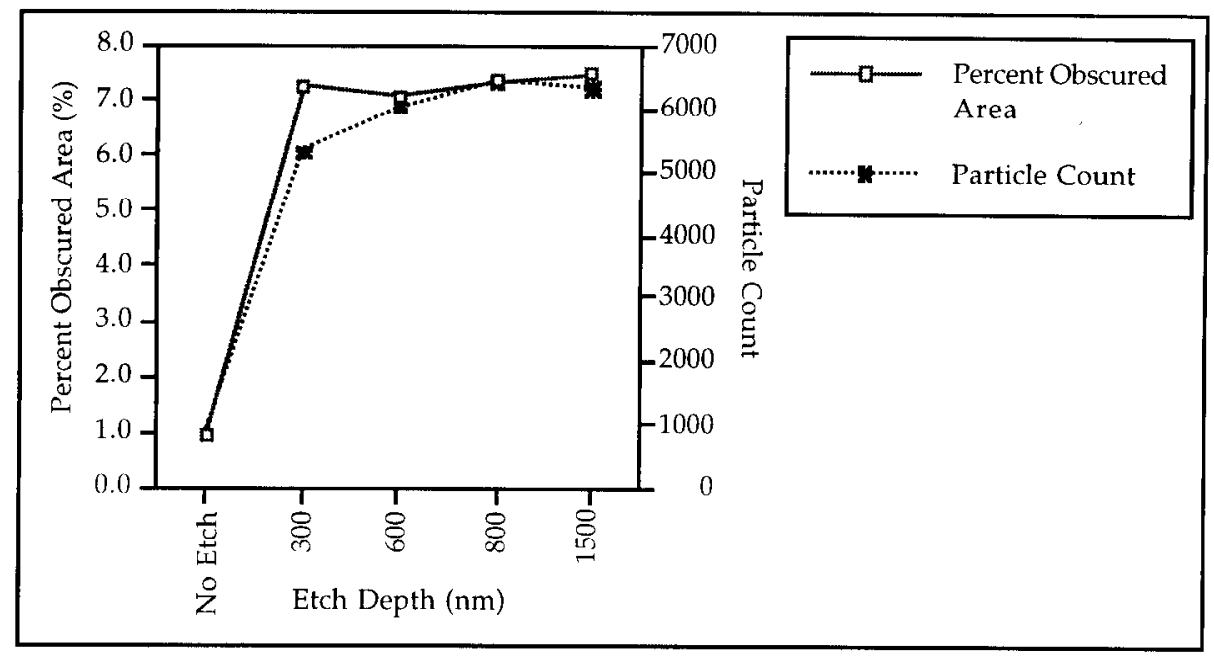

Figure 8. Comparison of the TIRM analysis of percent obscured area and particle count as a function of etch depth for side 1 of the Vendor $2, \mathrm{CeO}_{2}$ polished fused silica substrate.

\section{CONCLUSIONS}

The effects of wet etch processing on laser-induced damage of fused silica surfaces has been studied. From analysis of the results the following conclusions were drawn.

- In general, a wet etch exposes sub-surface damage while improving or maintaining laser damage performance levels. The benefits of etching must be evaluated for each polishing process.

- For $\mathrm{CeO}_{2}$ polished parts 1 and 2 an etch of $300 \mathrm{~nm}$ to $600 \mathrm{~nm}$ generally removes gray haze and exposes sub-surface damage consistent with the model shown in Figure 1. In some cases, however, gray haze-like damage inexplicably reappeared at deeper etch depths.

- For $\mathrm{CeO}_{2}$ polished part 2 an etch of $300 \mathrm{~nm}$ increased the R:1 damage performance to levels similar to that observed on $\mathrm{ZrO}_{2}$ polished part 3. For both parts 2 and 3 the exposed sub-surface defects (quantified using TIRM) did not adversely effect the damage performance. This may support the model that etching results in clean, blunted cracks which are benign to laser irradiation.

- For part 1 the R:1 performance was erratic. It is proposed that the sub-surface damage on this part was significant enough that the etching did not effectively blunt or clean the cracks. Unfortunately part 1 was not TIRM characterized for comparison to the other parts.

\section{ACKNOWLEDGMENTS}

The authors wish to thank Leslie Summers for her work etching the parts used in these experiments.

Work performed under the auspices of the United States Department of Energy by Lawrence Livermore National Laboratory under Contract No. W-7405-ENG-48. 


\section{APPENDIX A}

A.1. TIRM Images - Vendor $2, \mathrm{CeO}_{2}$ polished fused silica substrate.

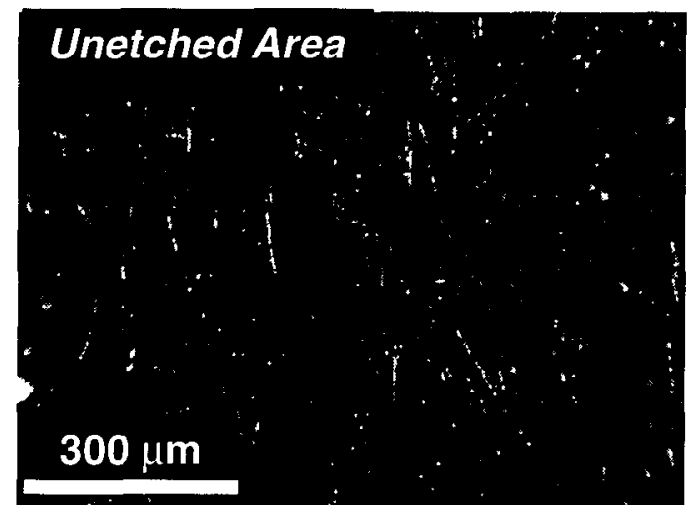

Figure A.1.1. Vendor 2, TIRM image of unetched region.

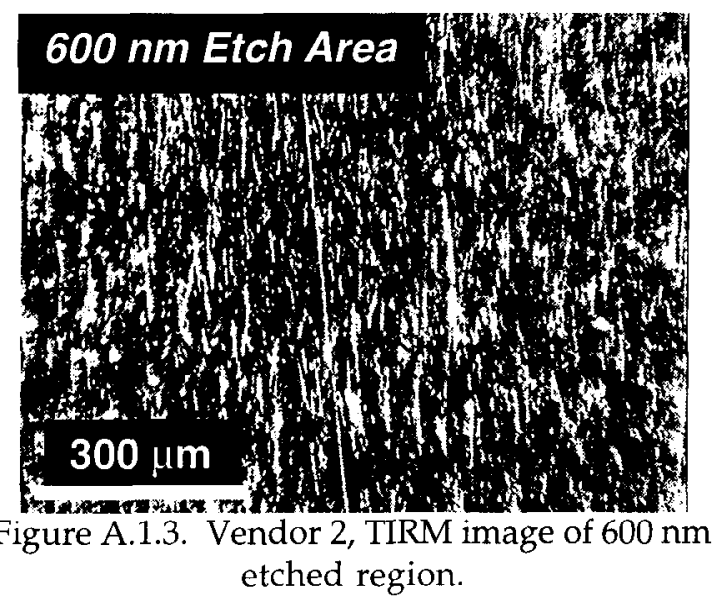

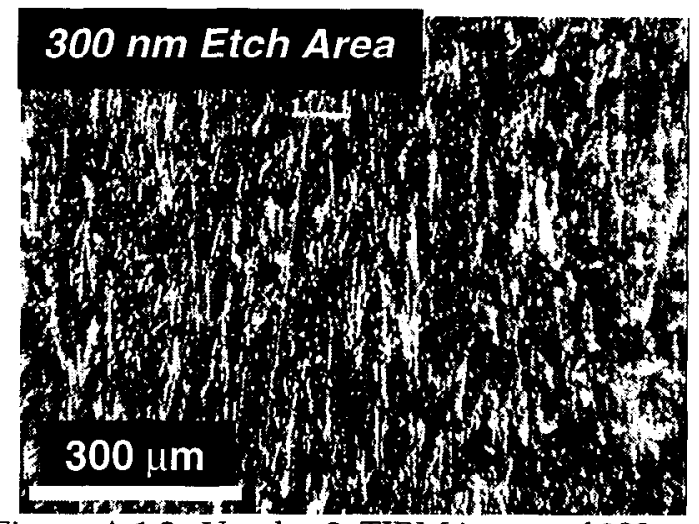

Figure A.1.2. Vendor 2, TIRM image of $300 \mathrm{~nm}$ etched region.

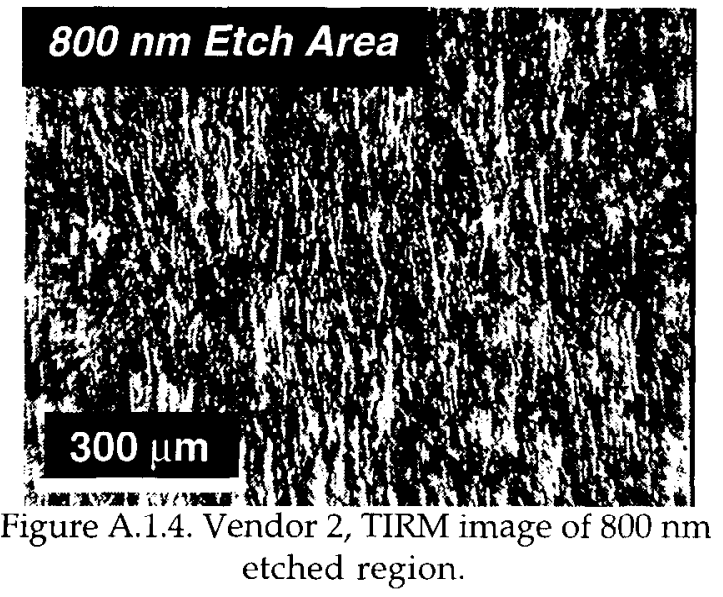

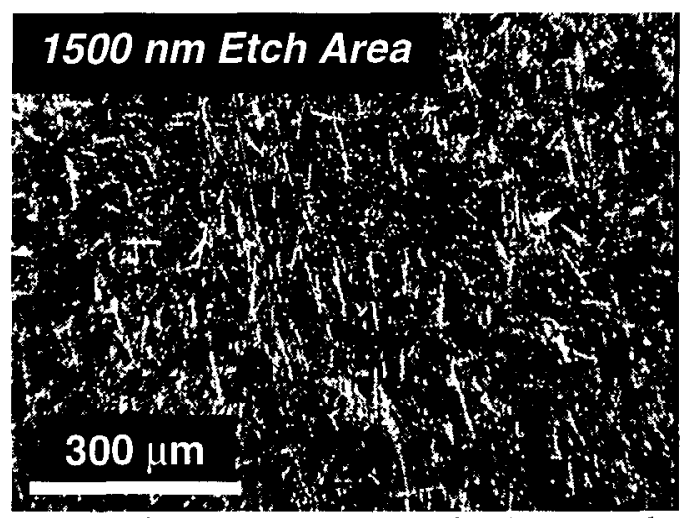

Figure A.1.5. Vendor 2, TIRM image of $1500 \mathrm{~nm}$ etched region. 
A.2. TIRM Images - Vendor $3, \mathrm{ZrO}_{2}$ polished fused silica substrate.

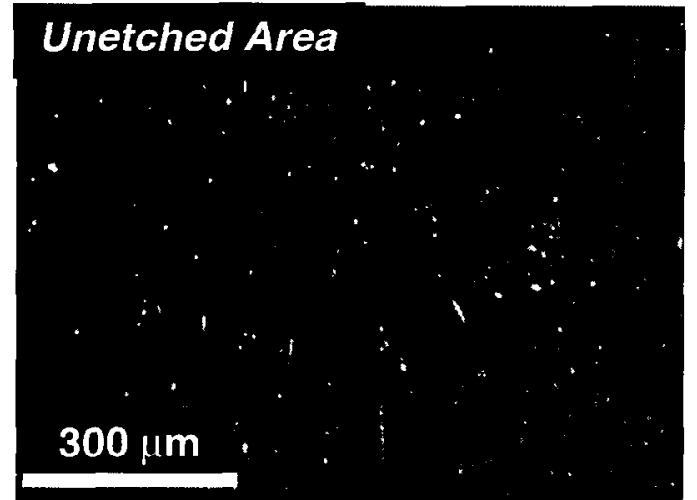

Figure A.2.1. Vendor 3, TIRM image of unetched region.

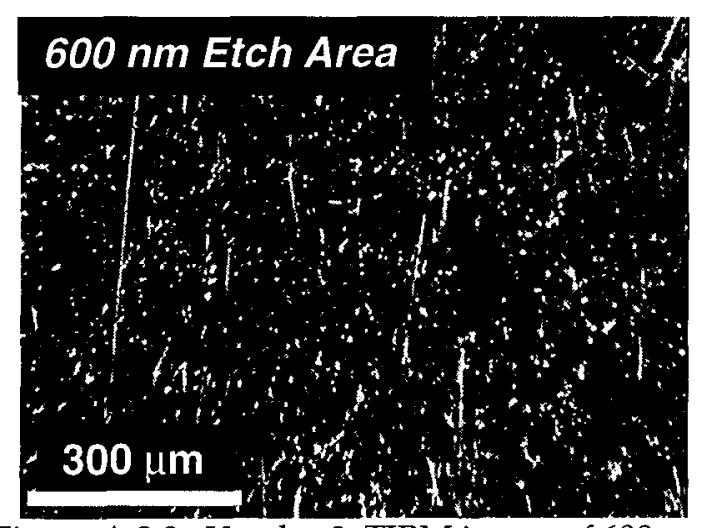

Figure A.2.3. Vendor 3, TIRM image of $600 \mathrm{~nm}$ etched region.

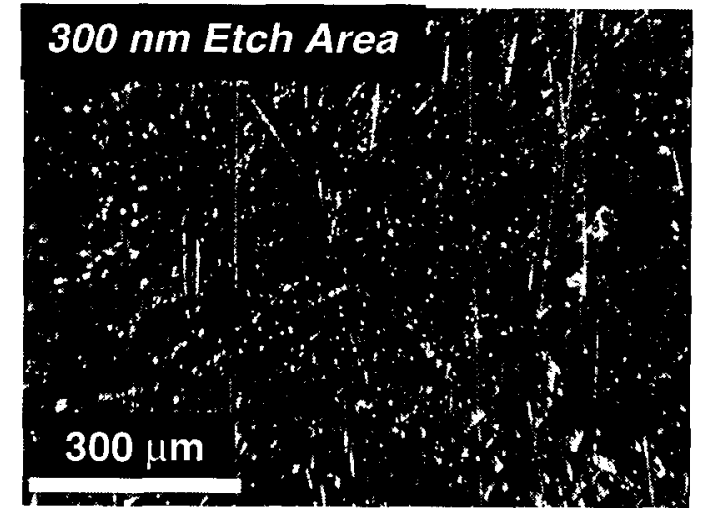

Figure A.2.2. Vendor 3, TIRM image of $300 \mathrm{~nm}$ etched region.

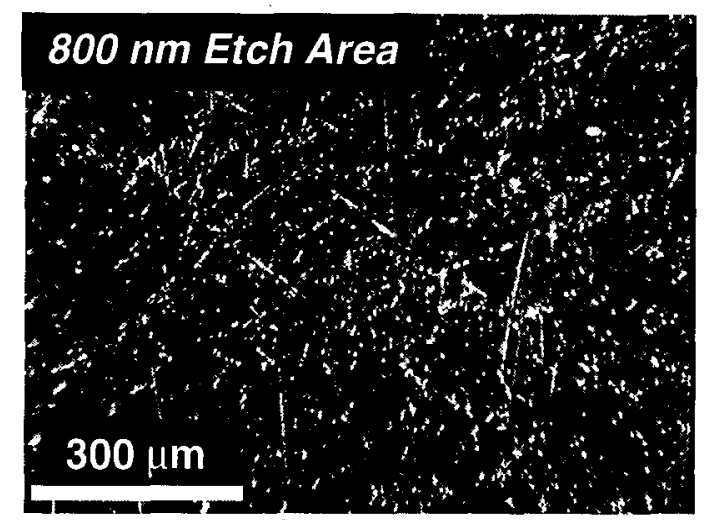

Figure A.2.4. Vendor 3, TIRM image of $800 \mathrm{~nm}$ etched region.

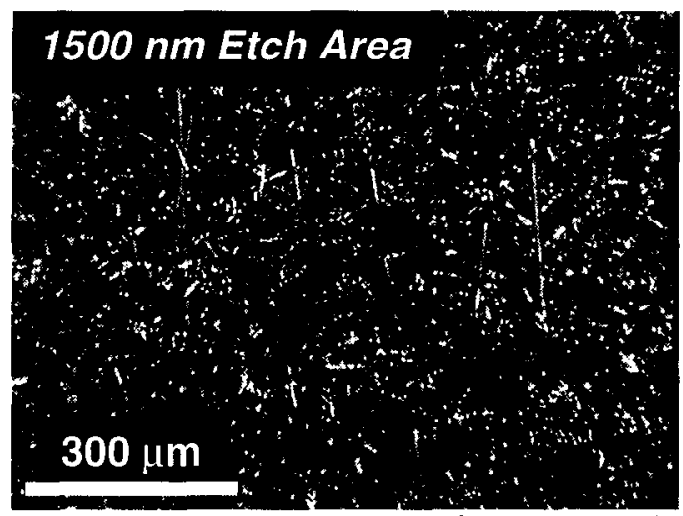

Figure A.2.5. Vendor 3, TIRM image of $1500 \mathrm{~nm}$ etched region. 


\section{REFERENCES}

1. D.W. Camp, M.R. Kozlowski, L.M. Sheehan, M. Nichols, M. Dovik, R. Raether, I. Thomas. "Subsurface damage and polishing compound affect the 355-nm laser damage threshold of fused silica surfaces," Laser-Induced Damage in Oplical Materials-1997, SPIE Vol. 3244, pp. 356-364, October 1997.

2. L.M. Sheehan, M.R. Kozlowski, D.W. Camp. “Application of Total Internal Reflection Microscopy for Laser Damage Studics on Fused Silica," Laser-Induced Damage in Optical Materials-1997, SPIE Vol. 3244, pp. 282-295, October 1997.

3. L.M. Sheehan, S. Schwartz, C.L. Battersby, R. Dickson, R. Jennings, J. Kimmons, M.R. Kozlowski, S. Maricle, R. Mouser, F. Rainer, M. Runkel, Z. Wu. “Automated Damage Test Facilitics for Materials Development and Production Optic Quality Assurance at Lawrence Livermore National Laboratory," These Proceedings, September 1998.

4. J. Hue, P. Garrec, J. Dijon, P. Lyan. "R-on-1 automatic mapping: a new tool for laser damage testing," Laser-Induced Damage in Optical Materials-1995, SPIE Vol. 2714, pp. 90-101, October 1995.

5. J. Hue, J. Dijon, P. Lyan. "CMO YAG laser damage test facility," Laser-Induced Damage in Optical Materials-1995, SPIE Vol. 2714, pp. 102-113, October 1995.

6. F.Y. Genin, L.M. Sheehan, J.M. Yoshiyama, Lawrence Livermore National Laboratory; J. Dijon, P. Garrec, LETI/CEA/DOPT. "Statistical study of UV-laser-induced failure of fused silica," LaserInduced Damage in Optical Materials-1997, SPIE Vol. 3244, pp. 155-163, October 1997.

7. J.M. Yoshiyama, F.Y. Genin, A. Salleo, I.M. Thomas, M.R. Kozlowski, L.M. Sheehan, I.D. Hutcheon, D.W. Camp. "Effects of polishing, etching, cleaving, and water leaching on the UV laser damage of fused silica," Laser-Induced Damage in Optical Materials-1997, SPIE Vol. 3244, pp. 331-340, October 1997.

8. A. Salleo, F.Y. Genin, J.M. Yoshiyama, C.J. Stolz, M.R. Kozlowski. “Laser-induced damage of fused silica at $355 \mathrm{~nm}$ initiated at scratches," Laser-Induced Damage in Optical Materials-1997, SPIE Vol. 3244, pp. 341-347, October 1997. 